\title{
Proteomic analysis of rat brains in a model of neuropathic pain following exposure to electroconvulsive stimulation
}

\author{
Chihiro Kamagata, Yosiaki Tsuboko, Tadashi Okabe, Chiyo Sato, and Atsuhiro Sakamoto \\ Department of Anesthesiology, Nippon Medical School
}

(Received 12 November 2010; and accepted 18 December 2010)

\begin{abstract}
Some reports have shown that electroconvulsive shock therapy is effective for treating refractory neuropathic pain. However, its mechanism of action remains unknown. This study analyzes changes in protein expression in the brainstems of neuropathic pain model rats with or without electroconvulsive stimulation (ECS). A neuropathic pain model rat is produced by chronic constrictive injury (CCI) of the sciatic nerve. An ECS was administered to rodents once daily for 6 days after the CCI operation. After ECS, the latency to withdrawal from thermal stimulation was significantly increased. The expression of several proteins was changed after CCI. Ten proteins that increased after CCI then had decreased expression levels (close to control) after ECS, and 8 proteins that decreased after CCI then had increased expression levels (close to control) after ECS. In conclusion, ECS improved thermal hypersensitivity in a rat CCI model. Proteomic analysis showed that altered expression levels of proteins in the brainstem of CCI model rats returned to close to control levels after ECS, including many proteins associated with pain. This trend suggests an association of ECS with improved hypersensitivity, and these results may help elucidate the mechanism of this effect.
\end{abstract}

Electroconvulsive shock therapy (ECT) has been used widely as an effective and established treatment for refractory depression and schizophrenia, although the mechanism of action of this treatment has not been clarified precisely. Many recent studies in the psychiatric field have suggested that the expression levels of the genes for various cerebral neurotransmitters would change after ECT. This change in gene expression might be a possible mechanism of action of ECT $(2,24,35,40)$. Also, some reports have shown that ECT is effective for treating refractory neuropathic pain $(5,16,22,36$, 37). However, ECT has not been performed as a general treatment for neuropathic pain because the evidence for its therapeutic effect is insufficient, ow-

Address correspondence to: Chihiro Kamagata Department of Anesthesiology, Nippon Medical School, 1-1-5 Sendagi, Bunkyo-ku, Tokyo 113-8603, Japan Tel: +81-3-5814-6243, Fax: +81-3-5685-3077

E-mail: kamagata@nms.ac.jp ing to a lack of data from large-scale controlled trials. Side effects, such as amnesia and injury from ECT, make this option rather unpopular (1). The mechanism of action of ECT in treating neuropathic pain has not been examined sufficiently, and thus remains unclear. We have previously shown that electroconvulsive stimulation (ECS) improves symptoms in rats with neuropathic pain. In the same study we also demonstrated that neuropeptide $\mathrm{Y}$ (NPY) expression in the brain was altered (28).

Brainstem tissue was selected for our studies because it contains important nuclei involved in descending inhibition and facilitation of nociceptive or pain transmission, as well as ascending pain transmission and integration with higher structures such as the limbic system. The brainstem nuclei involved in descending control or ascending integration include the rostral ventromedial medulla (RVM), the parabrachial nuclei, the dorsal reticular nuclei and the solitary tract nucleus (25).

We undertook a comprehensive study to clarify 
the mechanism of action of ECT in treating neuropathic pain. To do this, we examined changes in protein expression in the brainstem after ECS in a rat model of neuropathic pain produced by chronic constrictive injury (CCI) of the sciatic nerve. We used proteomic fractionation by 2-dimensional electrophoresis (2-DE) and differential in-gel electrophoresis (DIGE), followed by mass spectrometry (MS) to analyze the protein expression. To our knowledge, this is the first comprehensive report to study the mechanism underlying the effect of ECS on thermal hypersensitivity. The aim was to identify the proteins with altered expression levels in the brainstem after ECS in a rat model of neuropathic pain. Identifying these proteins should be valuable for understanding the mechanism of action of ECT in treating neuropathic pain.

\section{MATERIALS AND METHODS}

Production of a neuropathic pain model. The experimental procedures were approved by the institutional committee on Laboratory Animals of the Nippon Medical School (approval number 22-043) and were performed under the guidelines of the International Association for the Study of Pain (9). Male Sprague-Dawley rats (6-7 weeks of age, weighing 200-250g; Saitama Experimental Animals, Saitama, Japan) were used for all experiments. Rats were housed in clear plastic cages with sawdust bedding at standard room temperature under a $12 \mathrm{~h}$ light/dark cycle. All rats received food and water ad libitum. We divided the rats into three groups; 1) a group of rats undergoing no procedure (control group, $\mathrm{n}=6)$; 2) a group of CCI model rats to which ECS was not administered (CCI group, $\mathrm{n}=6$ ); and 3) a group of CCI model rats to which ECS was administered (CE group, $n=6$ ).

Experimental neuropathy was produced according to a method described in detail elsewhere (4). All surgical procedures were performed on rats that were deeply anesthetized with sodium pentobarbital $(50 \mathrm{mg} / \mathrm{kg}$ intraperitoneally). The left (ipsilateral) common sciatic nerve was exposed in the left midthigh and loosely ligated using $4-0$ silk thread in four regions, at about $1 \mathrm{~mm}$ intervals, to cause CCI. The right (contralateral) sciatic nerve was similarly exposed but not ligated.

Electroconvulsive stimulation. An ECS was administered transauricularly using a metal forceps as previously described $(24,35,41,47)$. ECS was administered to the $\mathrm{CE}$ group of rats once daily for 6 days from the 7 th to the 12 th postoperative day using a pulse generator (57800 ECT Unit; Ugo Basile, Comero, Italy) (frequency 100 pulses; pulse width $0.5 \mathrm{~ms}$; shock duration $0.8 \mathrm{~s}$; current $50 \mathrm{~mA}$ ). The shock elicited a full tonic-clonic seizure lasting 20 $30 \mathrm{~s}$ in all rats. Rats in the CCI group were exposed to the forceps, but without application of current.

Behavioral tests. Two behavioral tests (thermal and mechanical stimulation tests) were performed eight times to assess the pain threshold as previously described $(38,41)$. These eight times were: the day before surgery (Day 0); 2, 4 and 6 days after the surgery (Day 2, Day 4 and Day 6); 15 min before the second, fourth and sixth ECS (Day 8, Day 10 and Day 12); and $48 \mathrm{~h}$ after the last ECS (Day 14) (Fig. 1). The Plantar Test (Model 7370, Ugo Basile) was used to examine thermal hyperalgesia. Each rat was placed on a glass plate with radiant heat equipment (a $50 \mathrm{~W}$ halogen reflector bulb) underneath. After the acclimation period, radiation heat was applied to either the contralateral or ipsilateral hindpaw pad independently. The latency of paw withdrawal from thermal stimuli was measured three times at $5 \mathrm{~min}$ intervals and the average value was used as the latency of the response. Mechanical allodynia was measured using a set of von Frey filaments (Touch-test sensory evaluator; Muromachi Kikai, Saitama, Japan) with bending forces ranging from 1.0 to $23.0 \mathrm{~g}$. Each rat was placed on a metallic mesh floor, covered with a plastic box, and a von Frey filament was applied from under the mesh floor to the plantar surface of either the contralateral or ipsilateral hindpaw. Each paw was stimulated

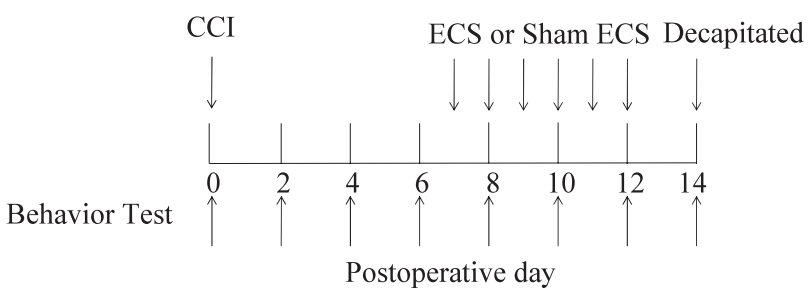

Fig. 1 Experimental protocol. Neuropathic pain was produced by chronic constrictive injury $(\mathrm{CCl})$ of the sciatic nerve. Using a pulse generator, an electroconvulsive shock (ECS) was administered to rodents once daily for 6 days on days 7-12 after the $\mathrm{CCl}$ operation. Thermal and mechanical stimulation tests were performed to assess pain thresholds on the day before surgery (Day 0); 2, 4 and 6 days after the surgery (Day 2, Day 4 and Day 6), 15 min before the second and fourth and sixth ECS (Day 8, Day 10 and Day 12), and $48 \mathrm{~h}$ after the last ECS (Day 14). Rats were decapitated $48 \mathrm{~h}$ after the last stimulation, the brains were rapidly removed and the brainstems were separated. 
with each filament five times at 10 second intervals in the individual trials. The weakest force $(\mathrm{g})$ inducing withdrawal of the stimulated paw at least three times in each trial was referred to as the paw withdrawal threshold. The difference in latency values for the two sides (difference score) was calculated as follows: difference score $=$ latency on the contralateral side - latency on the ipsilateral side.

Differential in-gel electrophoresis. Rats were decapitated $48 \mathrm{~h}$ after the last stimulation. The brains were rapidly removed and the brainstems were separated as previously described (3). The cerebellum of the hindbrains was removed. The brainstem was defined as the area from the caudal medulla (cranial to cervical 1 spinal cord) to the area parallel to the cranial aspect of the cerebellum just caudal to the midbrain and at the most cranial aspect of the third ventricle. Brainstems were immediately frozen in liquid nitrogen and stored at $-80^{\circ} \mathrm{C}$.

As described above, three groups of rats were examined. For each of the three groups, a total of 18 two-dimensional gels were produced for DIGE analysis. Each gel contained three different fluorescently labeled samples as previously described (32). An equal amount of protein homogenate from each of the three groups was pooled and labeled with the Cy2 (cyanine 2) dye. This served as the internal standard used in all 18 gels. Aliquots of the six controls were pooled and labeled with $\mathrm{Cy} 3$ (cyanine 3) dye to serve as the internal control sample. Finally, samples of all groups were labeled individually with Cy5 (cyanine 5) dye.

Sample preparation and labeling. For each individual brainstem tissue sample, lysis buffer ( $7 \mathrm{M}$ urea, $2 \mathrm{M}$ thiourea, 4\% CHAPS) and $1 \mathrm{mM}$ protease inhibitors (GE Healthcare Amersham Biosciences, Uppsala, Sweden) were added. The tissue was homogenized and centrifuged at $12,000 \times g$ for $15 \mathrm{~min}$ to remove nuclei and undissolved materials. The supernatants were centrifuged for $1 \mathrm{~h}$ at 10,000 $\times g$ and then collected. The protein homogenate was quantitated at $595 \mathrm{~nm}$ using the Bradford method (BioRad, Hercules, CA, USA). The Cy2, Cy3, and Cy5 labeling followed standard methods for minimal labeling. Briefly, the powdered Cy2, Cy3, or Cy5 dyes were dissolved in dimethylformamide (Sigma-Aldrich, St. Louis, MO, USA) to a final concentration of $1 \mathrm{mM}$. An aliquot of $50 \mu \mathrm{g}$ protein from each sample (pooled or individual) was labeled with 400 pmol of dye. Labeling was performed for $30 \mathrm{~min}$ on ice in the dark, before the reactions were quenched by adding $10 \mathrm{mM}$ lysine $(1 \mathrm{~mL}$ for each $400 \mathrm{pmol}$ of dye) for $10 \mathrm{~min}$ on ice in the dark. The quenched $\mathrm{Cy} 2, \mathrm{Cy} 3$, and $\mathrm{Cy} 5$ labeled samples (each containing $50 \mu \mathrm{g}$ protein) were then pooled and mixed with rehydration buffer $(7 \mathrm{M}$ urea, $2 \mathrm{M}$ thiourea, 4\% CHAPS, 2\% DTT (Sigma-Aldrich) to a final volume of $450 \mu \mathrm{L}$.

2-Dimensional electrophoresis. For the first dimension, isoelectric focusing (IEF) gradient strip gels were used. The $450 \mu \mathrm{L}$ samples were passively rehydrated into $24 \mathrm{~cm} \mathrm{pH} \mathrm{4-7} \mathrm{IPG} \mathrm{strips} \mathrm{(GE} \mathrm{Health-}$ care Amersham Biosciences) for $10 \mathrm{~h}$, followed by IEF using an IPGphor IEF unit (GE Healthcare Amersham Biosciences) for a total of $14800 \mathrm{Vh}$. The second-dimension, SDS-PAGE, was performed on $20 \mathrm{~cm} \times 24 \mathrm{~cm} 12.5 \%$ polyacrylamide gels using low-fluorescence glass plates. Electrophoresis was carried out using an Ettan DALTsix system (GE Healthcare Amersham Biosciences) at $6 \mathrm{~W} 80 \mathrm{~V}$ for $1 \mathrm{~h}$ followed by $12 \mathrm{~W} 150 \mathrm{~V}$ for $14 \mathrm{~h}$ in the dark. Gels were scanned immediately using the same setting and scanner in all cases.

Imaging and data processing. The differentially labeled DIGE gels were imaged at a resolution of $100 \mu \mathrm{m}$ separately by dye-specific excitation and emission wavelengths using a Typhoon 9400 Variable Mode Imager (GE Healthcare Amersham Biosciences). The gel intensities were kept in the linear range of 60,000-90,000 pixels/gel for image capture. Tagged image file format images were cropped and exported for analysis using the DeCyder v5.0 suite of software tools (GE Healthcare Amersham Biosciences). The differential in-gel analysis (DIA) module was used to identify protein spots and quantitatively compare the expression ratio of each individual protein spot-feature from $\mathrm{Cy} 5$ to the $\mathrm{Cy} 3$ labeled sample on a given gel after normalization to the Cy2 signal. This in-gel normalization reduces the requirement for technical repeats and enhances quantitative sensitivity (23). Spots are matched across gels by a combination of automated detection and manual examination. Briefly, a group of 200-250 spots in each gel of the entire group of 18 gels were matched to those in an arbitrary master gel by eye using the common $\mathrm{Cy} 2$ channel. These manually matched spots were evenly distributed across the gel and then served as landmarks for the DIGE DeCyder software to automatically match the rest of the spots on each gel. Matches were confirmed manually, and the processes were repeated iteratively. The DIA datasets for each individual gel were then 
collectively analyzed using the biological variation analysis (BVA) module, which allowed for matching across gels using the common $\mathrm{Cy} 2$ channel. This allows for reporting the volume of $\mathrm{Cy} 2, \mathrm{Cy} 3$, and Cy5 channels in all gels (spot volume = spot intensity/gel intensity) and for comparing protein migration patterns. Images and intensity data were collected as text limited files.

Mass spectroscopic identification. Two-dimensional gels were stained with Deep Purple Total Protein Stain (GE Healthcare Amersham Biosciences). In this procedure, gels were fixed $1 \mathrm{~h}$ after electrophoresis in $7.5 \%$ acetic acid and $10 \%$ methanol at room temperature. Gels were washed with $35 \mathrm{mM}$ sodium hydrogen carbonate and $300 \mathrm{mM}$ sodium carbonate at room temperature for $30 \mathrm{~min}$ with gentle agitation and then stained with Deep Purple Total Protein Stain for $1 \mathrm{~h}$ at room temperature in the dark. Gels were washed twice in $7.5 \%$ acetic acid for $15 \mathrm{~min}$ at room temperature in the dark.

Proteins of interest were robotically excised, equilibrated with $100 \mathrm{mM}$ ammonium bicarbonate for $20 \mathrm{~min}$ and dehydrated with two $10 \mathrm{~min}$ incubations with $100 \%$ acetonitrile in a 96-well plate format using Ettan Spot Picker and Digester workstations (GE Healthcare Amersham Biosciences). Dehydrated gel plugs were manually digested in-gel with $25 \mathrm{mM}$ sequencing grade modified trypsin protease (Promega, Madison, WI, USA) in $50 \mathrm{mM}$ ammonium bicarbonate for $16 \mathrm{~h}$ at $37^{\circ} \mathrm{C}$. Tryptic peptides were then extracted from the gel plugs in two cycles of $1 \%$ trifluoroacetic acid using the Ettan Digester workstation and dried by vacuum centrifugation. Peptides were reconstituted in $20 \mu \mathrm{L} 0.1 \%$ trifluoroacetic acid.

The resulting digested proteins were subjected to a high-pressure liquid chromatography separation on the chromatography system (MAGIC 2002; Michrom BioResources, Auburn, CA, USA). This chromatography system was coupled via a HTSPAL (CTC Analytics, Zwingen, Switzerland) to an ion trap MS (LCQ DECA XP; Thermo Finnigan, CA, USA). The resulting MS and MS/MS spectra of peptide ions were searched using MASCOT software (www.matrix-science.com). The peptide species count is the number of peptides used for the MASCOT scoring report. Any MASCOT score $>70$ is considered significant.

Statistical analysis. The latencies and threshold values in behavioral tests are expressed as means \pm standard deviation (SD). A paired $t$-test compared those values between the ipsilateral and contralateral sides. An unpaired $t$-test compared the difference score between the CE and CCI groups. Dunnett's test for multiple comparisons compared latencies, threshold values, or difference scores obtained in behavioral tests performed before the operations with those obtained in tests performed after the operations. $P<0.05$ is considered to be statistically significant. Also, CyDye-stained gels were digitized and the images were analyzed using DeCyder 2D software (GE Healthcare Amersham Biosciences). A one-way ANOVA (analysis of variance) followed by a Student-Newman-Keuls post hoc test was used to test for differences between the control and CCI groups, and between the CCI and CE groups. All results were reported as means $\pm \mathrm{SD}$, and $P<0.01$ was considered statistically significant.

\section{RESULTS}

\section{Behavioral tests}

Compared with the values on Day 0, latencies of paw withdrawal from thermal stimulation (Figs. 2A, 2B) and paw withdrawal thresholds in response to mechanical stimulation on the ipsilateral side (Figs. 3A, 3B) were decreased on Day 2, 4, 6, 8, 10 and 12. After ECS, the latencies of paw withdrawal from thermal stimulation on the ipsilateral side were increased on Day 14 in the CE group (Fig. 2A) and the difference score was significantly decreased on day 14 (Fig. 2C). Paw withdrawal thresholds in response to mechanical stimulation were not significantly changed after ECS (Fig. 3A). The results show that ECS is effective for treating thermal hypersensitivity, but not for treating mechanical allodynia.

\section{Protein fraction and 2-dimensional map}

In the scanned gels from the brainstem region, both volume and area could be determined for approximately 2500 spots. To establish a significant area of overlapping between the maps, a subset of 1400 representative spots was chosen.

There were 32 proteins in the CCI group with significantly increased expression compared with the control group, and each protein was up-regulated with an approximately 1.2-1.4 fold change (Table 1 ). Based on their physiologic function, these regulated proteins can be roughly subdivided into fundamental categories, such as: proteins related to cellular homeostasis and metabolism; neuronal function proteins; heat shock proteins, chaperones, and antioxidants; proteins related to cell cycle, apoptosis, 


\section{Thermal hypersensitivity}

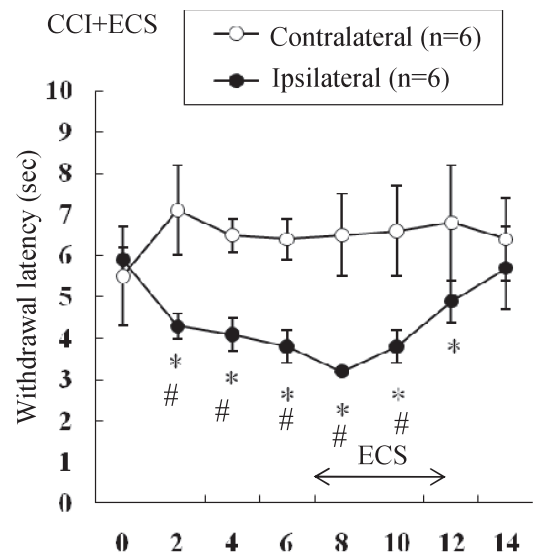

【A】 Postoperative day

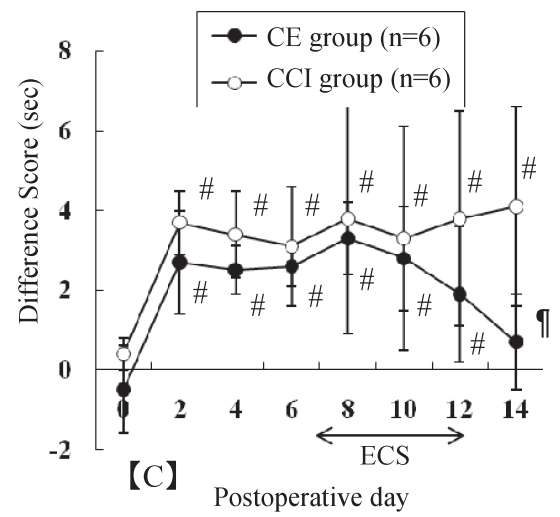

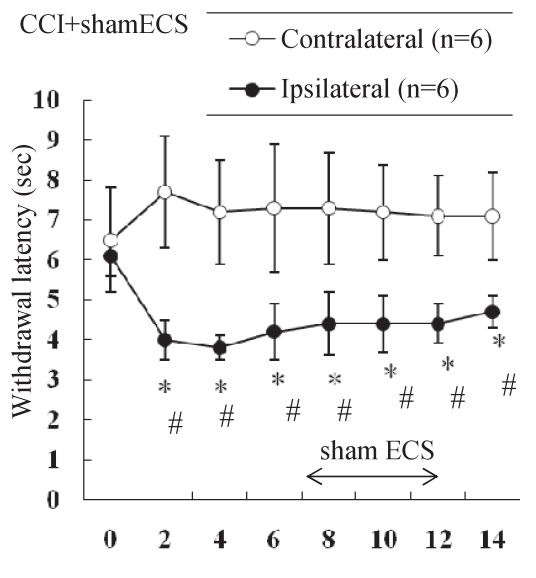

【B】 Postoperative day

Fig. 2 Effects of electroconvulsive shock (ECS) administered to chronic constrictive injury $(\mathrm{CCl})$ model rats $(A)(n=6)$ and the effects of $\mathrm{CCl}$ procedure $(B)(n=6)$ on thermal hypersensitivity. Thresholds for foot withdrawal on the ipsilateral and contralateral sides in response to thermal stimuli applied to the corresponding hindpaw pad in CCI rats are shown. Difference scores were calculated as the value of the withdrawal latency on the ipsilateral side subtracted from the latency on the contralateral side (C) (CE group, $n=6 ; C C l$ group, $n=6$ ). The degree of reduction of thermal hyperalgesia by ECS is statistically significant (Day 14). ${ }^{*} P<0.05$, compared with values on the contralateral side on the same days by a paired $t$-test; " $P<0.05$, compared with the $\mathrm{CCl}$ group by an unpaired $t$-test; ${ }^{\#} P<0.05$, compared with the values on the preoperative day (Day 0 ) by Dunnett's multiple comparisons. Values are means \pm standard deviation.

and neurodegeneration; or proteins related to the immune system. Among these proteins, 10 proteins had significantly decreased expression in the $\mathrm{CE}$ group compared with the CCI group, with expression levels reduced to close to control levels (approximately $0.9-1.2$ fold change compared with the control group). The name, function and expression ratio of each protein is tabulated in Table 2. RAP1 (GTP-GDP dissociation stimulator 1), CNDP dipeptidase 2, ATP synthase beta subunit, phosphoglycerate kinase (PGK), 3'-5'-bisphosphate nucleotidase 1, Ppal protein, and inositol monophosphatase 1 were reduced to control levels. Dihydrolipoamide S-acetyltransferase, malate dehydrogenase 1 , and the subunit $\mathrm{d}$ of mitochondrial $\mathrm{H}^{+}$ATP synthase were reduced to close to control levels.

There were 17 proteins in the CCI group with significantly decreased expression compared with the control group, and each protein was downregulated with approximately $0.5-0.8$ fold change (Table 3). Among these proteins, 8 proteins had significantly increased expression in the $\mathrm{CE}$ group compared with the CCI group, with expression levels increased to close to control levels (approximately $0.7-1.1$ fold change compared with the control group). The name, function and expression ratio of each protein is tabulated in Table 4. Collapsin response mediator protein, rCRMP-4, alpha-internexin and glial fibrillary acidic protein (GFAP) were increased to control levels. Heat shock protein 4, 


\section{Mechanical allodynia}

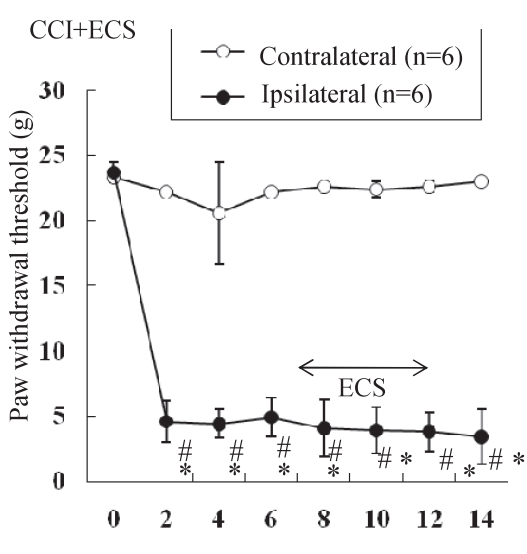

【A】 Postoperative day

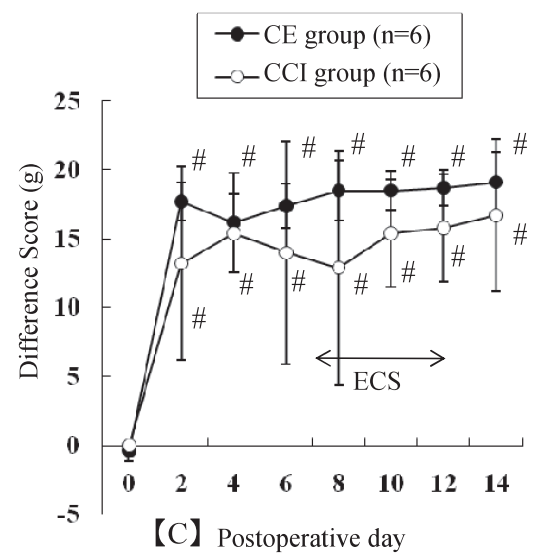

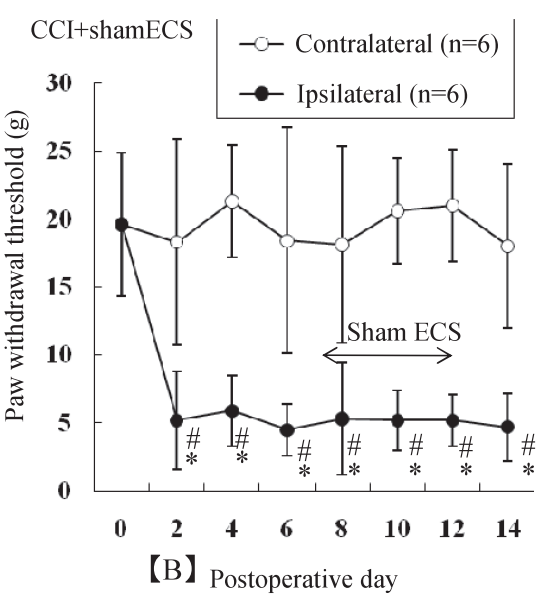

B】 Postoperative day

Fig. 3 Effects of electroconvulsive shock (ECS) administered to chronic constrictive injury (CCI) model rats $(A)(n=6)$ and the effects of the $\mathrm{CCl}$ procedure $(B)(n=6)$ on mechanical allodynia. Thresholds for foot withdrawal on the ipsilateral and contralateral sides in response to mechanical stimuli applied to the corresponding hindpaw pad in $\mathrm{CCl}$ rats are shown. Difference scores were calculated as the value of the withdrawal threshold on the ipsilateral side subtracted from the threshold on the contralateral side (C) (CE group, $n=6 ; C C l$ group, $n=6$ ). ECS was not effective for treating mechanical allodynia. ${ }^{*} P<0.05$ compared with values on the contralateral side on the same days, by a paired $t$-test; ${ }^{\sharp} P<0.05$ compared with the values on the preoperative day (Day 0 ) by Dunnett's multiple comparisons. Values are means \pm standard deviation.

grp75, aminopeptidase-B and the cytosolic branch chain aminotransferase (BCATc) were increased to close to control levels.

Eighteen proteins that were modulated following CCI returned to control levels after ECS. Images and Spot ID of these proteins were shown (Fig. 4).

\section{DISCUSSION}

In the present study, ECS is effective for treating thermal hypersensitivity, as has been reported in a previous study (41). The expression of several proteins in the brainstem was changed after CCI, and ECS regulated 18 proteins that changed after $\mathrm{CCI}$ to control expression level. In the following para- graphs, we will describe the relationship between these proteins and the mechanism of treating neuropathic pain.

CNDP dipeptidase 2 is a carnosine splitting enzyme that occurs in the brain and controls the level of carnosine (29). Carnosine has both antioxidant and neuroprotective effects against oxidative stress (34). Oxidative stress in the brain caused by CCI may increase the expression of CNDP dipeptidase 2 $(1.34 \pm 0.09$ compared to the control group). After ECS, the expression of this protein was reduced to the control level $(1.09 \pm 0.03$ compared to the control group). This suggests that the expression level can be modified by ECS, and the alteration of CNDP dipeptidase 2 might correlate with a mecha- 
Table 1 Proteins in the $\mathrm{CCl}$ group with significantly increased expression compared with the control group

\begin{tabular}{|c|c|c|c|c|c|c|}
\hline \multicolumn{6}{|c|}{ Protein identification } & \multirow{2}{*}{$\begin{array}{c}\text { Expression ratic } \\
\text { CCI }\end{array}$} \\
\hline $\begin{array}{l}\text { Spot } \\
\text { ID }\end{array}$ & $\begin{array}{l}\text { Protein } \\
\text { score } \\
\text { mascot }\end{array}$ & $\begin{array}{l}\text { Accession } \\
\text { No }\end{array}$ & $\begin{array}{c}\mathrm{Mw}(\mathrm{kDa}) / \\
\mathrm{pI}\end{array}$ & $\begin{array}{c}\text { Sequence } \\
\text { Coverage } \\
(\%)\end{array}$ & Protein & \\
\hline \multicolumn{7}{|c|}{ Proteins related to cellular homeostasis and metabolism } \\
\hline 820 & 107 & NM053748 & $83.3 / 5.12$ & 8 & dipeptidyl peptidase III & $1.18 \pm 0.05$ \\
\hline 1024 & 831 & NM130428 & $72.5 / 6.75$ & 26 & succinate dehydrogenase complex subunit A & $1.25 \pm 0.06$ \\
\hline 1044 & 555 & NM031025 & $67.6 / 8.76$ & 19 & dihydrolipoamide S-acetyltransferase & $1.28 \pm 0.04$ \\
\hline 1387 & 254 & AY034137 & $48.6 / 6.06$ & 14 & aldehyde dehydrogenase & $1.27 \pm 0.16$ \\
\hline 1400 & 284 & NM001025063 & $46.9 / 4.73$ & 18 & secernin 1 & $1.22 \pm 0.06$ \\
\hline 1421 & 544 & M19044 & $51.1 / 4.92$ & 27 & ATP synthase beta subunit & $1.24 \pm 0.12$ \\
\hline 1553 & 559 & NM001004250 & $53.5 / 5.57$ & 27 & ubiquinol-cytochrome c reductase core protein I precursor & $1.36 \pm 0.10$ \\
\hline 1689 & 104 & M31788 & $44.9 / 7.53$ & 7 & phosphoglycerate kinase (PGK) & $1.66 \pm 0.08$ \\
\hline 1692 & 165 & NM001005383 & $46.1 / 5.95$ & 12 & aminoacylase 1 (ACY1) & $1.27 \pm 0.03$ \\
\hline 1711 & 569 & BC166998 & $47.0 / 6.06$ & 35 & Sucla2 protein & $1.15 \pm 0.05$ \\
\hline 1814 & 146 & NM171990 & $33.4 / 5.58$ & 12 & 3'-5'-bisphosphate nucleotidase 1 & $1.33 \pm 0.18$ \\
\hline 1940 & 278 & NM053638 & $40.0 / 6.47$ & 17 & isocitrate dehydrogenase 3 alpha precursor & $1.15 \pm 0.07$ \\
\hline 2007 & 553 & NM012595 & $36.8 / 5.7$ & 41 & lactate dehydrogenase B (LDH B) & $1.16 \pm 0.13$ \\
\hline 2085 & 526 & NM033235 & $36.6 / 6.16$ & 34 & malate dehydrogenase 1 & $1.24 \pm 0.30$ \\
\hline 2100 & 238 & ВC099794 & $38.2 / 6.42$ & 21 & Ppa1 protein & $1.19 \pm 0.05$ \\
\hline 2166 & 235 & NM080585 & $33.6 / 5.3$ & 21 & N-ethylmaleimide-sensitive factor attachment protein alpha & $1.25 \pm 0.17$ \\
\hline 2485 & 249 & D10021 & $18.8 / 5.78$ & 45 & subunit $\mathrm{d}$ of mitochondrial $\mathrm{H}^{+}$ATP synthase & $1.31 \pm 0.09$ \\
\hline \multicolumn{7}{|c|}{ Neuronal function proteins } \\
\hline 1295 & 364 & NM001107728 & $52.6 / 5.53$ & 21 & RAP1 (GTP-GDP dissociation stimulator 1) & $1.24 \pm 0.12$ \\
\hline 1377 & 193 & NM001010920 & $53.1 / 5.43$ & 15 & CNDP dipeptidase 2 & $1.34 \pm 0.09$ \\
\hline 2246 & 249 & NM032057 & $30.8 / 5.17$ & 30 & inositol monophosphatase 1 & $1.16 \pm 0.04$ \\
\hline \multicolumn{7}{|c|}{ Heat shock proteins, chaperones, and antioxidant proteins } \\
\hline 816 & 779 & NM001005550 & $80.3 / 5.65$ & 28 & NADH dehydrogenase Fe-S protein 1 & $1.17 \pm 0.07$ \\
\hline 1150 & 650 & CH473989 & $60.1 / 5.38$ & 30 & chaperonin subunit 8 isoform CRA & $1.39 \pm 0.11$ \\
\hline 1155 & 565 & NM001004078 & $59.9 / 5.51$ & 24 & chaperonin containing TCP 1 subunit 5 & $1.23 \pm 0.04$ \\
\hline 1225 & 449 & M26653 & $55.3 / 6.19$ & 21 & glucose-6-phosphate dehydrogenase & $1.32 \pm 0.17$ \\
\hline 1326 & 594 & NM001005905 & $57.7 / 6.01$ & 26 & chaperonin containing TCP 1 & $1.19 \pm 0.08$ \\
\hline 1429 & 466 & CH473991 & $49.4 / 6.23$ & 25 & rCG53214 isoform CRA & $1.46 \pm 0.20$ \\
\hline 1526 & 775 & ВС090069 & $47.4 / 6.16$ & 47 & enolase 1 & $1.44 \pm 0.02$ \\
\hline 1548 & 379 & $\mathrm{CH} 473964$ & $34.9 / 4.87$ & 22 & enolase 2 gamma isoform CRA & $1.24 \pm 0.12$ \\
\hline 1559 & 753 & NM139325 & $47.5 / 5.03$ & 44 & enolase 2 & $1.37 \pm 0.05$ \\
\hline 1923 & 204 & NM199495 & $40.7 / 7.64$ & 12 & NADH dehydrogenase 1 alpha subcomplex 10 precursor & $1.47 \pm 0.08$ \\
\hline 1980 & 254 & NM022297 & $31.8 / 5.75$ & 15 & dimethylarginine dimethylaminohydrolase 1 (DDAH1) & $1.21 \pm 0.10$ \\
\hline \multicolumn{7}{|c|}{ Proteins related to the immune system } \\
\hline 869 & 314 & & & & glycyl-tRNA synthetase & $1.37 \pm 0.16$ \\
\hline
\end{tabular}

$\mathrm{n}=6$ in each group. Values are mean \pm standard deviation. All proteins listed above are significantly increased compared with the control group $(P<0.01)$.

Expression ratio: Relative expression level of the protein in the CCI group of rats compared with the control group.

CCI: chronic constrictive injury. MW: molecular weight. pI: isolelectric point.

nism for treating neuropathic pain.

Inositol monophosphatase 1 is associated with phosphatidyl inositol metabolism. Its activation of the metabolic pathway mediated by serotonin via the $5 \mathrm{HT}_{2}$ receptor has an antidepressive effect (11, $31,33)$. Serotonin $(5 \mathrm{HT})$ is part of the descending inhibitory system in the central nervous system, but 5 HT might be inhibitory or facilitatory $(30,42,44$,
49). The increased expression level of inositol monophosphatase 1 in the brainstem after CCI $(1.16 \pm$ 0.04 compared to the control group) and the return to the control level after ECS $(1.03 \pm 0.08$ compared to the control group) suggest that ECS has an effect on the descending inhibitory system and improves neuropathic pain.

ATP synthase beta subunit and subunit d of mito- 
Table 2 Proteins with significantly decreased expression in the CE group compared with the CCI group

\begin{tabular}{|c|c|c|c|c|}
\hline \multicolumn{3}{|c|}{ Protein identification } & \multicolumn{2}{|c|}{ Expression ratio } \\
\hline $\begin{array}{l}\text { Spot } \\
\text { ID }\end{array}$ & Protein & Function & CCI & $\mathrm{CE}$ \\
\hline 1044 & dihydrolipoamide S-acetyltransferase & $\begin{array}{l}\text { Part of the mitochondrial pyruvate dehydrogenase com- } \\
\text { plex }\end{array}$ & $1.28 \pm 0.04 *$ & $1.13 \pm 0.03 *$ \\
\hline 1295 & $\begin{array}{l}\text { RAP1 (GTP-GDP dissociation stim- } \\
\text { ulator 1) }\end{array}$ & $\begin{array}{l}\text { GTP-binding protein involved in the control of cell-cell } \\
\text { and cell-matrix adhesion }\end{array}$ & $1.24 \pm 0.12 *$ & $0.97 \pm 0.09$ \\
\hline 1377 & CNDP dipeptidase 2 & Neuroprotection protein & $1.34 \pm 0.09^{*}$ & $1.09 \pm 0.03$ \\
\hline 1421 & ATP synthase beta subunit & ATP production & $1.24 \pm 0.12 *$ & $1.05 \pm 0.07$ \\
\hline 1689 & phosphoglycerate kinase (PGK) & $\begin{array}{l}\text { A transferase enzyme used in the seventh step of gly- } \\
\text { colysis }\end{array}$ & $1.66 \pm 0.08^{*}$ & $0.95 \pm 0.17$ \\
\hline 1814 & 3'-5'-bisphosphate nucleotidase 1 & $\begin{array}{l}\text { Protein of converting adenosine 3'-phosphate 5'-phos- } \\
\text { phosulfate (PAPS) to adenosine 5'-phosphosulfate (APS) } \\
\text { and 3'-phosphoadenosine 5'-phosphate (PAP) }\end{array}$ & $1.33 \pm 0.18^{*}$ & $1.07 \pm 0.06$ \\
\hline 2085 & malate dehydrogenase 1 & A pivotal enzyme in the malate aspartate shuttle & $1.24 \pm 0.30^{*}$ & $1.16 \pm 0.04^{*}$ \\
\hline 2100 & Ppa 1 protein & A mechanism favoring biosynthesis & $1.19 \pm 0.05^{*}$ & $0.95 \pm 0.15$ \\
\hline 2246 & inositol monophosphatase 1 & $\begin{array}{l}\text { Key enzyme of the phosphatidyl inositol signaling path- } \\
\text { way }\end{array}$ & $1.16 \pm 0.04 *$ & $1.03 \pm 0.08$ \\
\hline 2485 & $\begin{array}{l}\text { subunit } \mathrm{d} \text { of mitochondrial } \mathrm{H}^{+} \text {ATP } \\
\text { synthase }\end{array}$ & ATP production & $1.31 \pm 0.09^{*}$ & $1.22 \pm 0.04^{*}$ \\
\hline
\end{tabular}

$\mathrm{n}=6$ in each group. Values are mean \pm standard deviation. All proteins listed above are significantly decreased in the CE group compared with the CCI group $(P<0.01)$. Proteins of significantly changed compared with control group $(* P<0.01)$.

Expression ratio (CCI): Relative expression level of the protein in the CCI group of rats compared with the control group.

Expression ratio (CE): Relative expression level of the protein in the $\mathrm{CE}$ group compared with the control group.

$\mathrm{CE}$ : chronic constrictive injury (CCI) model rats to which an electroconvulsive shock (ECS) was administered.

chondrial $\mathrm{H}^{+}$ATP synthase are involved in ATP production. ATP is a significant intercellular messenger molecule that interacts with purinoceptors. Specifically, the P2X and P2Y receptors, which are localized in the central and peripheral nervous systems, play an important role in excitatory nociceptive processing $(6,21)$. The results of the present study showed that ATP synthase expression is increased by chronic pain (ATP synthase beta subunit, $1.24 \pm$ 0.12 compared to the control group; subunit $\mathrm{d}$ of mitochondrial $\mathrm{H}^{+}$ATP synthase, $1.31 \pm 0.09$ compared to the control group), but that it is restored to the same level as seen in the control group after ECS (ATP synthase beta subunit, $1.05 \pm 0.07$ compared to the control group; subunit $d$ of mitochondrial $\mathrm{H}^{+}$ATP synthase, $1.22 \pm 0.04$ compared to the control group). This suggests a correlation between ATP synthase levels and the effects of ECS on chronic pain.

Other proteins that demonstrated increased expression after CCI include RAP1/GTP-GDP dissociation stimulator 1 (related to neuronal function), phosphoglycerate kinase (PGK), 3'-5'-bisphosphate nucleotidase 1 , malate dehydrogenase 1 , and Ppa 1 protein (related to cellular homeostasis and metabolism). These proteins were reduced to control levels after ECS. However, their physiological roles to thermal hypersensitivity are unclear at this time.

Also we noted that some proteins for which expression decreased after CCI had increased expression levels (close to control levels) after ECS. The subsequent paragraphs describe these proteins.

$\mathrm{HSP}_{4}$ and grp75 are heat shock proteins that have increased expression and show a nerve-protective action in inflammation and various disorders $(8,15$, 19). Increased expression of these proteins has been found in the dorsal root ganglion (DRG) after nerve injury $(17,18,46,48)$. Expression of $\mathrm{HSP}_{4}$ and grp75 in the brainstem has not been reported previously, but in the present study their expression decreased in the brainstem after CCI $\left(\mathrm{HSP}_{4}, 0.75 \pm\right.$ 0.07 compared to the control group; grp75, $0.65 \pm$ 0.05 compared to the control group). The return of the expression levels of these proteins to close to control levels after ECS $\left(\mathrm{HSP}_{4}, 0.86 \pm 0.03\right.$ compared to the control group; grp75, $0.72 \pm 0.05$ compared to the control group) suggests that ECS can restore the neuroprotection provided by $\mathrm{HSP}_{4}$ and grp75.

Aminopeptidase- $\mathrm{B}$ is involved in the production of neuropeptide Y (NPY) (12). NPY is a neuropeptide that is widespread throughout the central nervous system (CNS), and studies show NPY could be related to pain $(10,13,45)$. Taylor et al. showed 
Table 3 Proteins in the $\mathrm{CCl}$ group with significantly decreased expression compared with the control group

\begin{tabular}{|c|c|c|c|c|c|c|}
\hline \multicolumn{6}{|c|}{ Protein identification } & \multirow{2}{*}{$\begin{array}{c}\text { Expression ratio } \\
\mathrm{CCI}\end{array}$} \\
\hline $\begin{array}{l}\text { Spot } \\
\text { ID }\end{array}$ & $\begin{array}{l}\text { Protein } \\
\text { score } \\
\text { mascot }\end{array}$ & $\begin{array}{l}\text { Accession } \\
\text { No }\end{array}$ & $\begin{array}{c}\mathrm{Mw}(\mathrm{kDa}) / \\
\mathrm{pI}\end{array}$ & $\begin{array}{c}\text { Sequence } \\
\text { Coverage } \\
(\%)\end{array}$ & Protein & \\
\hline \multicolumn{7}{|c|}{ Proteins related to cellular homeostasis and metabolism } \\
\hline 1040 & 193 & D10655 & $57.6 / 5.53$ & 13 & dihydrolipoamide acetyltransferase & $0.83 \pm 0.11$ \\
\hline 1338 & 267 & NM057213 & $56.8 / 5.57$ & 11 & vacuolar $\mathrm{H}^{+}$ATPase B2 & $0.72 \pm 0.05$ \\
\hline 1393 & 497 & M19044 & $51.1 / 4.92$ & 30 & ATP synthase beta subunit & $0.79 \pm 0.05$ \\
\hline 1642 & 488 & $\mathrm{CH} 474034$ & $36.1 / 6.27$ & 42 & creatine kinase brain isoform CRA a & $0.72 \pm 0.08$ \\
\hline 1743 & 83 & M18668 & $42.9 / 5.33$ & 5 & creatine kinase & $0.55 \pm 0.05$ \\
\hline \multicolumn{7}{|c|}{ Neuronal function proteins } \\
\hline 999 & 113 & D87515 & $73.2 / 5.47$ & 8 & aminopeptidase-B & $0.57 \pm 0.13$ \\
\hline 1397 & 424 & U03700 & $49.9 / 5.35$ & 26 & glial fibrillary acidic protein (GFAP) & $0.57 \pm 0.20$ \\
\hline 1646 & 88 & AF165887 & $41.2 / 7.2$ & 5 & cytosolic branch chain aminotransferase (BCATc) & $0.76 \pm 0.10$ \\
\hline \multicolumn{7}{|c|}{ Heat shock proteins, chaperones, and antioxidant proteins } \\
\hline 558 & 280 & NM001106428 & $55.0 / 5.5$ & 8 & heat shock protein 4 & $0.75 \pm 0.07$ \\
\hline 905 & 425 & S78556 & $73.9 / 5.87$ & 16 & grp75 & $0.65 \pm 0.05$ \\
\hline 940 & 1069 & M19141 & $71.0 / 5.37$ & 34 & heat shock protein 70 & $0.70 \pm 0.07$ \\
\hline 997 & 348 & CH479375 & $48.6 / 6.16$ & 22 & rCG57965 isoform CRA b & $0.77 \pm 0.09$ \\
\hline 1541 & 306 & NM139125 & $47.5 / 5.03$ & 16 & enolase 2 & $0.70 \pm 0.14$ \\
\hline \multicolumn{7}{|c|}{ Proteins related to cell cycle, apoptosis, and neurodegeneration } \\
\hline 1015 & 93 & U52095 & $62.5 / 6.61$ & 5 & collapsin response mediator protein & $0.75 \pm 0.17$ \\
\hline 1109 & 75 & U52104 & $39.3 / 5.08$ & 7 & rCRMP-4 & $0.50 \pm 0.20$ \\
\hline 1126 & 403 & X52017 & $55.7 / 5.2$ & 23 & alpha-internexin & $0.73 \pm 0.09$ \\
\hline 2161 & 150 & AF051895 & 33.9 / 4.99 & 12 & lipocortin V & $0.84 \pm 0.12$ \\
\hline
\end{tabular}

$\mathrm{n}=6$ in each group. Values are mean \pm standard deviation. All proteins listed above are significantly decreased compared with the control group $(P<0.01)$.

Expression ratio: Relative expression level of the protein in the CCI group of rats compared with the control group.

CCI: chronic constrictive injury. MW: molecular weight. pI: isolelectric point.

Table 4 Proteins with significantly increased expression in the CE group compared with the CCI group

\begin{tabular}{|c|c|c|c|c|}
\hline \multicolumn{3}{|c|}{ Protein identification } & \multicolumn{2}{|c|}{ Expression ratio } \\
\hline $\begin{array}{l}\text { Spot } \\
\text { ID }\end{array}$ & Protein & Function & $\mathrm{CCI}$ & $\mathrm{CE}$ \\
\hline 558 & heat shock protein 4 & Neuroprotection after a variety of stresses or injuries & $0.75 \pm 0.07^{*}$ & $0.86 \pm 0.03 *$ \\
\hline 905 & grp75 & Neuroprotection after a variety of stresses or injuries & $0.65 \pm 0.05^{*}$ & $0.72 \pm 0.05^{*}$ \\
\hline 999 & aminopeptidase-B & Production of neuropeptide Y (NPY) & $0.57 \pm 0.13^{*}$ & $0.70 \pm 0.08^{*}$ \\
\hline 1015 & collapsin response mediator protein & $\begin{array}{l}\text { A member of a family of proteins that are involved in } \\
\text { axonal growth }\end{array}$ & $0.75 \pm 0.17^{*}$ & $1.11 \pm 0.18$ \\
\hline 1109 & rCRMP-4 & $\begin{array}{l}\text { A member of a family of proteins that are involved in } \\
\text { axonal growth }\end{array}$ & $0.50 \pm 0.20^{*}$ & $1.16 \pm 0.08$ \\
\hline 1126 & alpha-internexin & $\begin{array}{l}\text { A neuronal intermediate filament protein implicated in } \\
\text { neurodegenerative disease }\end{array}$ & $0.73 \pm 0.09 *$ & $1.03 \pm 0.13$ \\
\hline 1397 & glial fibrillary acidic protein (GFAP) & $\begin{array}{l}\text { An intermediate filament protein found in the cytoskel- } \\
\text { eton of astroglia }\end{array}$ & $0.57 \pm 0.20^{*}$ & $0.85 \pm 0.23$ \\
\hline 1646 & $\begin{array}{l}\text { cytosolic branch chain aminotrans- } \\
\text { ferase (BCATc) }\end{array}$ & $\begin{array}{l}\text { Brain derived neurotrophic factor (BDNF) that are be- } \\
\text { lieved to have several actions in the CNS }\end{array}$ & $0.76 \pm 0.10^{*}$ & $0.85 \pm 0.05^{*}$ \\
\hline
\end{tabular}

$\mathrm{n}=6$ in each group. Values are mean \pm standard deviation. All proteins listed above are significantly increased in the CE group compared with the CCI group $(P<0.01)$. Proteins of significantly changed compared with control group $(* P<0.01)$.

Expression ratio (CCI): Relative expression level of the protein in the CCI group of rats compared with the control group.

Expression ratio (CE): Relative expression level of the protein in the CE group compared with the control group.

$\mathrm{CE}$ : chronic constrictive injury (CCI) model rats to which an electroconvulsive shock (ECS) was administered. 


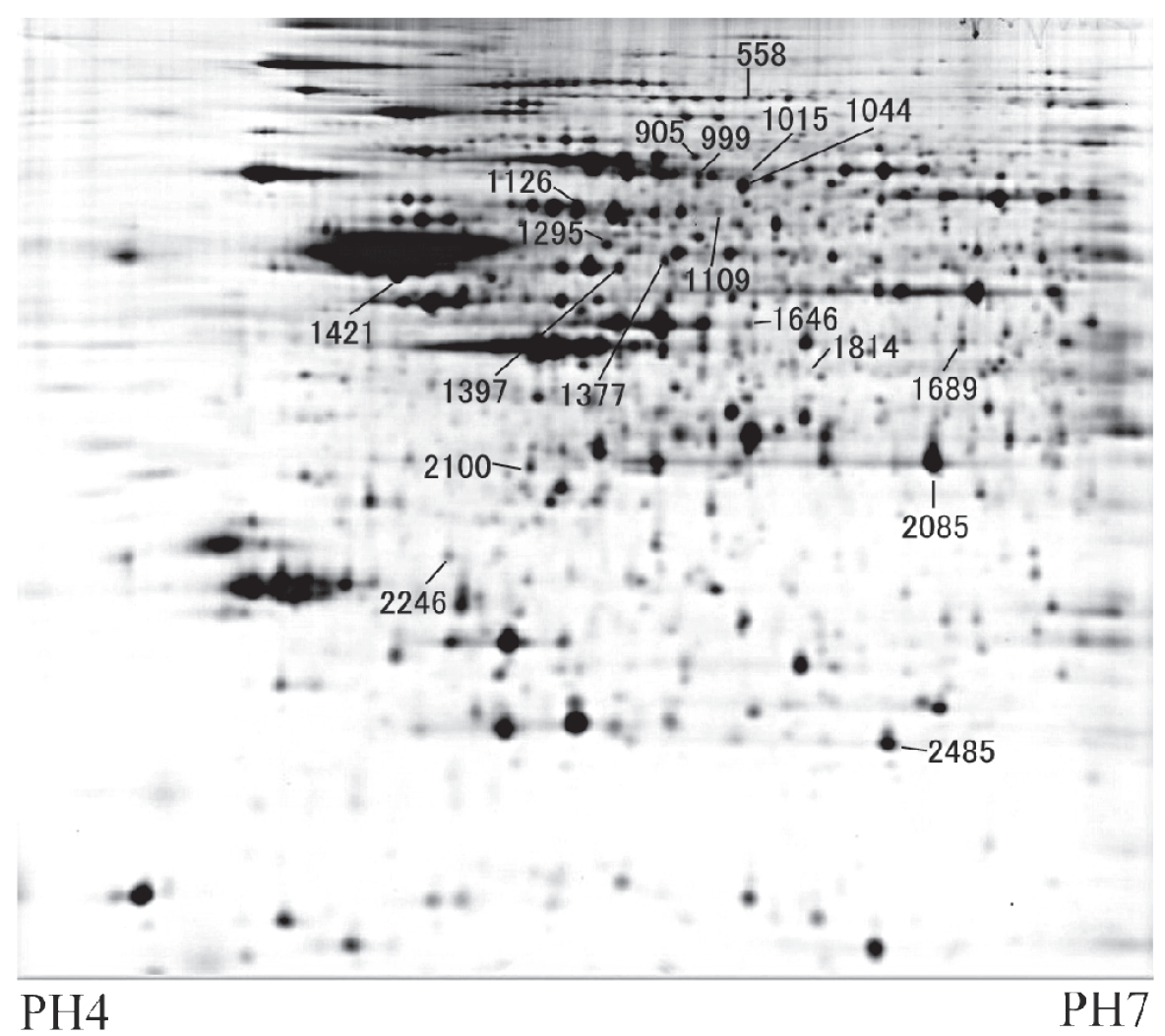

Fig. 4 A typical 2-dimensional map. Spots were marked by their spot ID numbers shown in Table 2 and Table 4.

that neuropathic pain was improved by administration of NPY to the RVM, and proposed that NPY would have an inhibitory action on pain (45). In a previous study performed in our facility using CCI model rats, the expression level of NPY decreased after CCI, but returned to the control level after ECS (28). In the present study, the trend of decreased expression after CCI $(0.57 \pm 0.13$ compared to the control group) and a return to close to the control level after ECS $(0.70 \pm 0.08$ compared to the control group) was found again. This correlates to an effect of ECS on chronic pain and NPY levels.

Glial fibrillary acidic protein (GFAP) is an intermediate filament protein of astrocytes, but whether changes in expression of this protein contribute to pain processing is not known. Expression of GFAP is increased in the periaqueductal gray matter and DRG in neuropathic pain model rats $(14,27,43)$. Although the decreased expression level $(0.57 \pm 0.20$ compared to the control group) of GFAP in the brainstem after CCI shows a different trend to that previously reported, the return to the control level $(0.85 \pm 0.23$ compared to the control group) after ECS suggests that ECS has an effect on astrocytes which improve hypersensitivity.
Cytosolic branch chain aminotransferase (BCATc) is associated with brain derived neurotrophic factors (BDNFs) that are believed to have several actions in the CNS (7). The decreased expression level of BCATc after CCI $(0.76 \pm 0.10$ compared to the control group) was increased to close to the control level after ECS $(0.85 \pm 0.05$ compared to the control group). This suggests a correlation between BCATc and the effects of ECS on chronic pain.

Collapsin response mediator proteins might be involved with axonal growth in the CNS (39). Alpha-internexin is a neuronal intermediate filament protein in the CNS that is involved in neurodegenerative diseases (20). These proteins that related to cell cycle, apoptosis, and neurodegeneration were altered greatly, and have a broad impact on the CNS, which may include involvement in hypersensitivity to pain.

Previously, a number of proteomic studies have been performed using different types of neuropathic pain models, and some proteins related to neuropathic pain have already been reported (26). In our study, we demonstrated that ECS improved thermal hypersensitivity, and 18 proteins that were modulated following CCI returned to control levels after 
ECS. These 18 proteins are involved in neuronal degeneration, regeneration and inflammatory processes like previous reports. Although we could not clearly make the interaction of those proteins mentioned above from our results, our findings strongly suggest that ECS affects neuropathic pain and expression of some proteins related to neuropathic pain. Further studies need to be conducted to reveal the correlation between thermal hypersensitivity and each individual protein.

In conclusion, ECS improved thermal hypersensitivity in a CCI rat model. The expression levels of eighteen proteins that were modulated following CCI, including CNDP dipeptidase 2, inositol monophosphatase 1, ATP synthase beta subunit, subunit d of mitochondrial $\mathrm{H}^{+}$ATP synthase, $\mathrm{HSP}_{4}$, grp75, aminopeptidase-B, GFAP and BCATc, returned to control levels after ECS. We expect that this trend is the key to understanding the mechanism of action of ECT in treating neuropathic pain.

\section{REFERENCES}

1. Abdi S, Haruo A and Bloomstone J (2004) Electroconvulsive therapy for neuropathic pain: a case report and literature review. Pain Physician 7, 261-263.

2. Altar CA, Laeng P, Jurata LW, Brockman JA, Lemire A, Bullard J, Bukhman YV, Young TA, Charles V and Palfreyman MG (2004) Electroconvulsive seizures regulate gene expression of distinct neurotrophic signaling pathways. $J$ Neurosci 24, 2667-2677.

3. Alzate O, Hussain SR, Goettl VM, Tewari AK, Madiai F, Stephens RL Jr and Hackshaw KV (2004) Proteomic identification of brainstem cytosolic proteins in a neuropathic pain model. Brain Res Mol Brain Res 128, 193-200.

4. Bennett GJ and Xie YK (1988) A peripheral mononeuropathy in rat that produces disorders of pain sensation like those seen in man. Pain 33, 87-107.

5. Bloomstein JR, Rummans TA, Maruta T, Lin SC and Pileggi TS (1996) The use of electroconvulsive therapy in pain patients. Psychosomatics 37, 374-379.

6. Burnstock G (2006) Purinergic P2 receptors as targets for novel analgesics. Pharmacol Ther 110, 433-454.

7. Castellano S, Casarosa S, Sweatt AJ, Hutson SM and Bozzi Y (2007) Expression of cytosolic branched chain aminotransferase (BCATc) mRNA in the developing mouse brain. Gene Expr Patterns 7, 485-490.

8. Cizkova D, Carmel JB, Yamamoto K, Kakinohana O, Sun D, Hart RP and Marsala M (2004) Characterization of spinal HSP72 induction and development of ischemic tolerance after spinal ischemia in rats. Exp Neurol 185, 97-108.

9. Covino BG, Dubner R, Gybels J, Kosterlitz HW, Liebeskind JC, Sternbach RA, Vyklicky L, Yamamura H and Zimmermann M (1980) Ethical standards for investigations of experimental pain in animals. Pain 9, 141-143.

10. Hökfelt T, Brumovsky P, Shi T, Pedrazzini T and Villar M (2007) NPY and pain as seen from the histochemical side. Peptides 28, 365-372.

11. Hoyer D, Waeber C, Schoeffter P, Palacios JM and Dravid A (1989) 5-HT1C receptor-mediated stimulation of inositol phosphate production in pig choroid plexus. A pharmacological characterization. Naunyn Schmiedebergs Arch Pharmacol 339, 252-258.

12. Hwang SR, O'Neill A, Bark S, Foulon T and Hook V (2007) Secretory vesicle aminopeptidase B related to neuropeptide processing: molecular identification and subcellular localization to enkephalin- and NPY-containing chromaffin granules. $J$ Neurochem 100, 1340-1350.

13. Ji RR, Zhang X, Wiesenfeld-Hallin Z and Hökfelt T (1994) Expression of neuropeptide $\mathrm{Y}$ and neuropeptide $\mathrm{Y}$ (Y1) receptor mRNA in rat spinal cord and dorsal root ganglia following peripheral tissue inflammation. $J$ Neurosci 14, 64236434.

14. Kim DS, Figueroa KW, Li KW, Boroujerdi A, Yolo T and Luo ZD (2009) Profiling of dynamically changed gene expression in dorsal root ganglia post peripheral nerve injury and a critical role of injury-induced glial fibrillary acidic protein in maintenance of pain behaviors. Pain 143, 114-122.

15. Kim DS, Lee SJ, Park SY, Yoo HJ, Kim SH, Kim KJ and Cho HJ (2001) Differentially expressed genes in rat dorsal root ganglia following peripheral nerve injury. Neuroreport 12, 3401-3405.

16. King JH and Nuss S (1993) Reflex sympathetic dystrophy treated by electroconvulsive therapy: intractable pain, depression, and bilateral electrode ECT. Pain 55, 393-396.

17. Klass MG, Gavrikov V, Krishnamoorthy M and Csete M (2008) Heat shock proteins, endothelin, and peripheral neuronal injury. Neurosci Lett 433, 188-193.

18. Komori N, Takemori N, Kim HK, Singh A, Hwang SH, Foreman RD, Chung K, Chung JM and Matsumoto H (2007) Proteomics study of neuropathic and nonneuropathic dorsal root ganglia: altered protein regulation following segmental spinal nerve ligation injury. Physiol Genomics 29, 215-230.

19. Krueger-Naug AM, Emsley JG, Myers TL, Currie RW and Clarke DB (2002) Injury to retinal ganglion cells induces expression of the small heat shock protein Hsp27 in the rat visual system. Neuroscience 110, 653-665.

20. Liem RK and Messing A (2009) Dysfunctions of neuronal and glial intermediate filaments in disease. J Clin Invest 119, $1814-1824$.

21. Liu XJ and Salter MW (2005) Purines and pain mechanisms: recent developments. Curr Opin Investig Drugs 6, 65-75.

22. Mandel MR (1975) Electroconvulsive therapy for chronic pain associated with depression. Am J Psychiatry 132, 632636.

23. Marouga R, David S and Hawkins E (2005) The development of the DIGE system: 2D fluorescence difference gel analysis technology. Anal Bioanal Chem 382, 669-678.

24. Mikkelsen JD and Woldbye DP (2006) Accumulated increase in neuropeptide $\mathrm{Y}$ and somatostatin gene expression of the rat in response to repeated electroconvulsive stimulation. $J$ Psychiatr Res 40, 153-159.

25. Millan MJ (2002) Descending control of pain. Prog Neurobiol 66, 355-474.

26. Niederberger E and Geisslinger G (2008) Proteomics in neuropathic pain research. Anesthesiology 108, 314-323.

27. Norman GJ, Karelina K, Zhang N, Walton JC, Morris JS and Devries AC (2010) Stress and IL-1beta contribute to the development of depressive-like behavior following peripheral nerve injury. Mol Psychiatry 15, 404-414.

28. Okabe T, Sato C, Matsumoto K, Ozawa H and Sakamoto A (2009) Electroconvulsive stimulation (ECS) increases the expression of neuropeptide Y (NPY) in rat brains in a model of neuropathic pain: a quantitative real-time polymerase chain 
reaction (RT-PCR) study. Pain Med 10, 1460-1467.

29. Otani H, Okumura A, Nagai K and Okumura N (2008) Colocalization of a carnosine-splitting enzyme, tissue carnosinase (CN2)/cytosolic non-specific dipeptidase 2 (CNDP2), with histidine decarboxylase in the tuberomammillary nucleus of the hypothalamus. Neurosci Lett 445, 166-169.

30. Oyama T, Ueda M, Kuraishi Y, Akaike A and Satoh M (1996) Dual effect of serotonin on formalin-induced nociception in the rat spinal cord. Neurosci Res 25, 129-135.

31. Pacheco MA, Stockmeier C, Meltzer HY, Overholser JC, Dilley GE and Jope RS (1996) Alterations in phosphoinositide signaling and G-protein levels in depressed suicide brain. Brain Res 723, 37-45.

32. Pan JZ, Xi J, Eckenhoff MF and Eckenhoff RG (2008) Inhaled anesthetics elicit region-specific changes in protein expression in mammalian brain. Proteomics 8, 2983-2992.

33. Pauwels PJ (2000) Diverse signaling by 5-hydroxytryptamine (5-HT) receptors. Biochem Pharmacol 60, 1743-1750.

34. Pekcetin C, Kiray M, Ergur BU, Tugyan K, Bagriyanik HA, Erbil G, Baykara B and Camsari UM (2009) Carnosine attenuates oxidative stress and apoptosis in transient cerebral ischemia in rats. Acta Biol Hung 60, 137-148

35. Ploski JE, Newton SS and Duman RS (2006) Electroconvulsive seizure-induced gene expression profile of the hippocampus dentate gyrus granule cell layer. J Neurochem 99, $1122-1132$.

36. Rasmussen KG and Rummans TA (2000) Electroconvulsive therapy for phantom limb pain. Pain 85, 297-299.

37. Rasmussen KG and Rummans TA (2002) Electroconvulsive therapy in the management of chronic pain. Curr Pain Headache Rep 6, 17-22.

38. Sato C, Sakai A, Ikeda Y, Suzuki H and Sakamoto A (2008) The prolonged analgesic effect of epidural ropivacaine in a rat model of neuropathic pain. Anesth Analg 106, 313-320.

39. Schweitzer J, Becker CG, Schachner M and Becker T (2005) Expression of collapsin response mediator proteins in the nervous system of embryonic zebrafish. Gene Expr Patterns $\mathbf{5}, 809-816$

40. Shen H, Numachi Y, Yoshida S, Fujiyama K, Toda S, Awata S, Matsuoka H and Sato M (2003) Electroconvulsive shock in- creases serotonin transporter in the rat frontal cortex. Neurosci Lett 341, 170-172.

41. Shibata M, Wakisaka S, Inoue T, Shimizu T and Yoshiya I (1998) The effect of electroconvulsive treatment on thermal hyperalgesia and mechanical allodynia in a rat model of peripheral neuropathy. Anesth Analg 86, 584-587.

42. Sommer C (2006) Is serotonin hyperalgesic or analgesic? Curr Pain Headache Rep 10, 101-106.

43. Sun T, Cui CB, Luo JG, Zhang L, Fu ZJ and Song WG (2010) Effect of electroacupuncture on the expression of spinal glial fibrillary acidic protein, tumor necrosis factor-alpha and interleukin-1beta in chronic neuropathic pain rats. Zhen $\mathrm{Ci}$ Yan Jiu 35, 6-12.

44. Suzuki R, Rygh LJ and Dickenson AH (2004) Bad news from the brain: descending 5-HT pathways that control spinal pain processing. Trends Pharmacol Sci 25, 613-617.

45. Taylor BK, Abhyankar SS, Vo NT, Kriedt CL, Churi SB and Urban JH (2007) Neuropeptide Y acts at Y1 receptors in the rostral ventral medulla to inhibit neuropathic pain. Pain 131, 83-95.

46. Willis D, Li KW, Zheng JQ, Chang JH, Smit A, Kelly T, Merianda, TT, Sylvester J, van Minnen J and Twiss JL (2005) Differential transport and local translation of cytoskeletal, injury-response, and neurodegeneration protein mRNAs in axons. $J$ Neurosci 25, 778-791.

47. Woldbye DP, Greisen MH, Bolwig TG, Larsen PJ and Mikkelsen JD (1996) Prolonged induction of c-fos in neuropeptide Y- and somatostatin-immunoreactive neurons of the rat dentate gyrus after electroconvulsive stimulation. Brain Res 720, 111-119.

48. Zhang Y, Wang YH, Zhang XH, Ge HY, Arendt-Nielsen L, Shao JM and Yue SW (2008) Proteomic analysis of differential proteins related to the neuropathic pain and neuroprotection in the dorsal root ganglion following its chronic compression in rats. Exp Brain Res 189, 199-209.

49. Zhao ZQ, Chiechio S, Sun YG, Zhang KH, Zhao CS, Scott M, Johnson RL, Deneris ES, Renner KJ, Gereau RW 4th and Chen ZF (2007) Mice lacking central serotonergic neurons show enhanced inflammatory pain and an impaired analgesic response to antidepressant drugs. J Neurosci 27, 6045-6053. 